\title{
The role and rationality of religion: the case of Brazil
}

\begin{abstract}
This paper analyses the importance of religion for a population and the motives for following a religion. To perform the analyses, oficial statistical data of Brazil on the evolution of religion, crime and death rates as well as messages from internet networking groups related to losses were utilized. Pascal bet and behavior economics theory was utilized on the investigation. Although religion has experienced a growth in diversity and in the number of adepts, neither crime rates, loses, development or welfare totally explains the reasons for embracing a religion. Sites created by mothers to the beloved sons they violently lost and messages and answers left by participants on those network groups, shows that not only pain is responsible for the growth of religion but hope based on a rational decision. The paper confirms behavior theory and concludes that no matter the level of development or pain, it is rational to engage in some religion as it contributes to ones improvement of well-being. In other words it is not only the culture, tradition or the level of development that determines religiosity but rationality.
\end{abstract}

Keywords: religion, behavior economics, development, culture, rationality, population
Volume I Issue 4 - 2017

\author{
Eveline Carvalho BS \\ Department of Sociology, Federal University of Ceará, Brazil
}

Correspondence: Eveline Carvalho BS, Department of Sociology, Federal University of Ceará, Brazil, Email eveline@ufc.br

Received: September 0I, 2017 | Published: November 03, 2017

\section{Introduction}

Religion has long played a very important role in different cultures and it is natural to imagine that when there is more instability or the deaths and crime rates are growing there are more loses and therefore more people look for consolation in religion. If that was the case there should be much more religiosity in Latin America less developed countries which is not true. In fact the United States register a very high percentage of people, especially Christians which represents $78.3 \%$ of the population Pew Research Center ${ }^{1}$ that consider religion an important part in their lives although it has one of the lowest crime rates of the world. So culture, family traditions as well as other reasons might play a very important role in the decision of joining a religion to strengthen ones believes.

Brazil has been traditionally a very religions country and there is even a popular quote that says that: "God is Brazilian". This translates people's beliefs and the importance of region for the country. The proportion of Catholics remains the majority, although declining in recent decades. In fact recent data show the growth of different religious groups but especially the evangelical population that increased from $9.0 \%$ in 1991 to $22.2 \%$ of the population on 2010 . There has been an impressive growth in the number of prisoners in Brazil however this increase did not meant a decrease in crime rate. In fact Brazil has increased the crime rates from 11.7 in 1980 to 26.2 in 2010 per 100,000 Murray et al. ${ }^{2}$ and has registered a growth in deaths mainly of young people.

This situation might be a result of illiteracy rates, poverty and lack of opportunities that again may lead to growth in religion adepts. But besides that, the need for religion has also might have a rational motive, more than a sentimental one which is driven by ones believes. This paper analyses the importance of religion for the population and the motives for following a religion related to crime and deaths rates using the Brazilian case. To perform the analyses, statistical data and comments from internet networking groups related to loses were used. Pascal bet and theory on behavior economics were also utilized on the investigation. Besides this introduction on the second section there is a literature review, section three discusses on the evolution of religiosity, section four comments on other changes experienced by the Brazilian population that influences religiosity, section five brings a dialogue between reason and faith, and section six presents the final considerations.

\section{Literature Review}

Religion is important for the economy growth and many studies have been performed showing that relation, as Robert Barro et al., ${ }^{3}$ on Religion and Economic Growth, that states that religious beliefs influence individual behavior that enhance economic performance. But economics and religion have generally been seen as separate field even considering that Adam Smith ${ }^{4}$ known as "the father of economy" introduced religion in his classic as of 1776, The Wealth of Nations: "The expense of the institutions for education and religious instruction, is likewise, no doubt, beneficial to the whole society, and may, therefore, without injustice, be defrayed by the general contribution of the whole society." p. 877.

A new generation of economists, the so called economists of religion, are following the footsteps of University of Chicago economist Becker, ${ }^{5}$ who won a Nobel prize for the application and use of economics analytical tools to the study ordinary things such as crime, drugs, and family interactions. Becker, ${ }^{5}$ puts an emphasis on the importance of the economic approach in analyzing the objectives of human behavior on the book, The Economic Approach to Human Behavior. For him the competition among the many denominations for capturing new members and maintaing its members is important as competition always induces competitors to try to better satisfy the wants of their customers. This might explain the growth of evangelical or protestant religions in many Latin American countries traditionally catholic.

On the discussion paper, Religion as a Determinant of Economic and Demographic Behavior in the United States, Lehrer, ${ }^{6}$ reviews and synthesizes the role of religion on various aspects of the economic and demographic behavior of the individuals and families in the United States, using a theoretical framework based on Becker ${ }^{5}$ contributions to the economics of the family. The study states that 
religious involvement has beneficial effects on health and wellbeing. Religiosity is reinforced and maintained by the transmission of religious beliefs from parents to children. As in Iannaccone: ${ }^{7}$ "Religion remains a very powerful force in contemporary society." And this powerful force might not depend on the level of growth and development. Religion involves rational choices and this extends even to suicide bombers who strike in the name of God Berman et al. ${ }^{8}$ So, people might be just as rational in their choices about religion as they are rational about choosing any other things as which carreer to follow, where should live and which house should buy.

\section{Evolution of religiosity}

For most countries religion has been characterized by both a wide diversity of religious beliefs and practices and by a high and increasing adherence level. In the United States for example, about eighty percent of Americans identify themselves with a religion and for the majority of Americans religion plays a very important role in their lives. Many faiths have flourished in the United States, including those of immigrant heritage, leading the United States to become one of the most religiously diverse countries in the world despite being a developed country. The majority of Americans, about 78\%, identify themselves as Christians. According to the American Religious Identification Survey, ${ }^{9}$ those who identify themselves as Catholics make up about $23,9 \%$ of the adult population, while evangelic or protestant account for another 54,3\%. In Latin America religion plays a very important role and the majority of the population is composed by Roman Catholic, however there has been a change concerning religiosity in many countries of the region. In 1900, evangelicals or Protestants represented about $1 \%$ of the population in Latin America, while by 2010 , they reached $17 \%$ of this population.

In Brazil, the results of the more recent Census of the country of 2010 conducted by the Brazilian Institute of Geography and Statistics ${ }^{10}$ show that the proportion of Catholics remains the majority, although declining in recent decades, from $83 \%$ in 1991 , to $73,6 \%$ in 2000 and to $64,6 \%$ in 2010 . The resukts also show the growth of other religious groups but especially the evangelical population that increased from $9,0 \%$ in 1991 to $15.4 \%$ in 2000 and reached $22.2 \%$ in 2010. Although the religious profile confirm the prevalence of the Catholic religion, the historic Catholic majority is losing supporters in Brazil. In fact the proportion of Catholics of the country once had represented almost the entire population in 1970 as the percentage of Catholics was $99.7 \%$ on that decade.

The change on the percentage of the catholic population and on the growth of less traditional religions shows the change in religiosity that the country is facing. Spiritualists that represented $1.3 \%$ of the population, or 2.3 million people in 2000 , came to $2.0 \%$, or 3.8 million, in 2010. The 2010 Brazilian Census also recorded an increase in the population who declared no religion. On 2000 this population accounted for almost 12.5 million people ( $7.3 \%$ of the total population of the country) and exceeded 15 million who declared no religion on 2010 , or $8.0 \%$ of the population appointinng to the growth in securalization. In the United States, $16,1 \%$ of the population is identified as "no religion" which indicates doubts about the existence of a God had grown rapidly specially among the youth.

\section{Changes experienced by the brazilian population that might interfere on religiosity}

Besides the change on religiosity many other changes have occurred in Brazil. From 1960 to 2010, the average number of sons per woman fell from 6.3 children to 1.9 children. These changes affect the population pyramid, with narrowing of the base and extending the top, reflecting an aging population, which is a feature of most developed countries. The Brazilians now lives about twenty-five years longer than he used to live on 1960. In fact, in 1960 the life expectancy of the Brazilian was 48 years of age and in 2010 was 73.4 years. Despite having extensive agricultural area, the Brazilian population is concentrated primarily in urban areas, about $84.4 \%$, where there is more violence and record high levels of crime. According to information from the National Council of Justice - CNJ, Brazil has the third largest prison population in the world, with 494,598 inmates behind only the United States, with 2,297,400 prisoners, and China, with 1,620,000 prisoners. From 2005 to 2011 there was a 37\% growth in the number of prisoners in Brazil however, according to the Information System (SIM) of the Ministry of Health, the increase in the prison population has not meant a decrease in crime.

In fact, even in small towns and less developed states, the crime rate is increasing. This is the case of the states of Maranhão and Piaui, whose homicide rates rose $242 \%$ and $203 \%$, respectively between 1996 and 2008. Increases of crime rates were also verified on Ceará state, which rate increased $122 \%$ over the same period, Rio Grande do Norte $178 \%$ and Sergipe $134 \%$. Some data on the level of employment and education puts a light on that cruel reality but does not explain the whole story. According to the IBGE 2010 census, $6.4 \%$ of the economically active population (EAP) is unemployed, representing 5 million Brazilians and among the workers about $20 \%$ survive with one minimum wage (around US $\$ 170,00$ per month) or less. Only in Sao Paulo nearly one million people live in slums or makeshift dwellings.

Illiteracy is not, less alarming. Today, there are still 13.9 million Brazilians aged 15 or older, that are considered illiterate and this is equivalent to $9.63 \%$ of the population, while in Argentina this percentage is $3 \%$, and in Chile, $4 \%$ which. The population of those two countries has a high level of religiosity as well as Brazil indicating that the level of religiosity is not directly related to illiteracy level. In Brazil there is still a significant educational gap between regions. While in Southeast illiterate represent 5.5\%, in the South, 5.1\%, in the Midwest, $7.2 \%$, in the North $11,2 \%$ and $19.1 \%$ in the northeast. According the data of the "Map of Violence 2012 - Children and Adolescents in Brazil", which analyzes information from the Ministry of Health on the causes of deaths of people between zero and 19 years of age, the growth rate of death among young people increased.

In 1980 the homicide of young people represented $11 \%$ of total deaths. In 2010 this rate accounted for nearly half of the total of deaths, $43 \%$. Among the Brazilian states the ones where there was a greater increase in murders of youth include Alagoas, with a rate of 34.8 homicides per 100 thousand inhabitants, Espírito Santo 33.8 and Bahia 23.8. The states that had the lowest rates were Santa Catarina 6.4, São Paulo 5.4 and Piaú 3.6. However there has been a kind of decentralization of violence. In big capitals, which concentrate most homicide cases, there is a reduction of murders of young people, while in smaller cities, the index has increased. In São Paulo, for example, between 2000 and 2012, rates have fallen from 36 homicides per 100 000 children and adolescents to 5.3 , a decline of $85.2 \%$. In the same period, the index soared over Natal city from 2.9 to 30.5 .

Brazil has been able to achieve the Millennium Development Goals as it has advanced significantly in the eight millennium goals yet the homicide of young people have not been following this trend since Brazil is in 4th place in the ranking of countries with the most 
murders of young people being Alagoas the more violent state for young people, and Piaui the safest state. Among the capitals, Maceió and Victoria have high rates: 79.8 and 76.8 murders per 100000 children and adolescents, nearly six times the national average. Data from the Ministry of Health states that in most cases, violence happens indoors. In over $60 \%$ of the time, the young offender is at home. Even among those over 15, who already have more movement outside the home, violence originates in homes in nearly $51.4 \%$ of cases, while in the streets occurs in $31.2 \%$ of cases. Accidents with motorcicles especially involving the younger population in Brazil is responsible for killing many boys and girls as well as alcoholism, drug involvement and armed robbery.

\section{A dialogue betwen reason and faith}

In the face of so much suffering in consequence of a lost of the loved ones, especially if they are still young, it is expected that people desolate and seek encoragement in religion. In the modern world the growth of internet use and social networking sites related to loses are also becoming increasingly common for people who had this experience. The objective of those channels is to share their feelings on the "facebook" or blogs specially created to address issues related to loss where participants can leave their messages and so share their pain. Research based on 527,783 messages left on sites prepared by mothers in honor of their children who died suddenly and at young age and whatsapp group shows that in $90 \%$ of cases the mothers who declare to believe in God tend to accept what happened, confident of salvation and the belief that one day will meet again the loved ones. On the other hand, people who have declared themselves not to believe in God show disinterest for life, family, work and normally reported health problems due to the loss experienced.

The traditional economic approach is based on the idea of the "homo economicus", described as a rational decision-maker, with unlimited capacity to process information and with relatively stable preferences. This approach considers that the market itself and its process of convergence to equilibrium are capable of solving the possible errors of decision. In contrast to the traditional idea, behavioral economics addresses a new view of the individual considering it as "homo psychologicus" where exogenous factors such as the influence of environment and emotional factors directly affect consumer decision and the idea of rationality. In this sense, Simon \& Tversky ${ }^{11,12}$ proposed the Prospect Theory that shows how people decide in situations of risk and uncertainty. Such a theory asserts that decisions are not always optimal, that our willingness to take risks depends on a context and that we prefer not to lose from gain, that is, our aversion to loss is greater than esteem for gain.

To investigate this last proposal of the theory, that we prefer not to lose from gain, that is, our aversion to loss is greater than esteem for gain, three questions where answered by 102 mothers of the above cited internet groups. The first question was: Do you agree that the intensity of sadness of the loss is much greater than the intensity of the happiness when there is gain? The second question was: Would you rather have never won your child so you do not have to suffer from his loss now? The thrird question was: Having a religion helped or did not bear the loss? For the first question the arguments were different but all answered yes, that the sorrow for loss is much greater than the joy of gain, corroborating the theory proposed by the behavioral economy. The arguments used to answer yes to the first question can be summarized as follows: yes. No one wants to lose. Nobody likes to get out of the comfort zone. It's hard to settle for loss. Sadness is intensified for various reasons and factors, so it is greater. Winning is fleeting, losing is forever.

For the second question to $90 \%$ answered no. The arguments of those who responded not were: No. I was benefited. What matters is the amount I received for the time I had. Losses are experiences that must pass. We learn from negative experiences. The $10 \%$ who answered yes to the second question argued that: yes. Not to see his son suffer. The third question asked was if having a religion helped or did not bear the loss. $96 \%$ of the respondents answered yes. And they argued that: when we confine ourselves to this life the loss seems infinite. But when we see life as a transient and do not end here in this dimension, it is easier to bear. Others have argued that: if we have faith we believe that our life is not ours. That our son before being ours is of God. That the children have returned to the Father's house and that we have not lost them definitively because there will be a reunion. $4 \%$ of respondents did not answer the third question.

Despite adherence to a religion seem as something related only to the feeling caused by a loss situation and inconvenience caused by addictions, drugs, prejudice and violence, is actually a rational decision. Decision theory assumes that people, human beings like us, are rational and so is the decision seeking strategies in different situations in which the outcome depends not only on the own strategy of an agent or player but also the strategies chosen by other agents involved in a game which consists of players, available strategies for these players, and a payment for each combination of strategy. Aiming to support the rationale behind the advancement of religion in Brazil and adaptation of Pascal ${ }^{13}$ is used presented as a normal matrix.

Using such rationality people decide on thousand of things intuitively and even on religion. So the question concerning religiosity should be if people should or not believe in God, and what could happen according to the decison choosen. This can be formulated on a game (Table). What should be the any one's rational strategy? Observe that believe is a rational strategy and is the equilibrium outcome of the game. Therefore it is rational to have faith, believe in God and choose a religion to follow. It is known that religion has a very strong cultural base but following a religion seems even more rational when violence and unsafety is present. ${ }^{14-20}$

Table After all god exists or does not exist

\begin{tabular}{lll}
\hline & God exists & God does not exist \\
\hline Believe & Go to heaven & $\begin{array}{l}\text { Have comfort in life and } \\
\text { consolation when needed }\end{array}$ \\
Do not believe & Go to hell & Nothing happens \\
\hline
\end{tabular}

Source: . ${ }^{13}$

\section{Final considerations}

Religion is where people tend to turn during desperate times as it is within human nature to search for a greater force when the world cannot provide any real answers or solutions to our problems. This does not mean however that underdeveloped countries with high instability or deaths rates are more religious. So, religiosity within a country is not caused by the level of development as it has cultural as well as rational motives. But development may be driven by religion as may make people more productive according to their beliefs. So, given that religion drives people's behavior and actions in a more productive direction, it is not possible to separate religion from development. The relationship between religion and 
development is likely to be beneficial as long as religious beliefs and practices promote moderation. It can also be stated that a peaceful coexistence of various religious groups within a country is an essential prerequisite for growth and prosperity which itself is a prerequisite for development. ${ }^{21-24}$

Economic development promotes job creation, education and improving basic living conditions and health, leading to consequent advance in the quality of life with reduction in mortality rates and crime. But even with the improvement of life people seek safe haven in their religions to thank and ask for grace. ${ }^{25}$ Moreover, higher levels of well-being may mean devoting more time to the things that no longer feeds the earthly well-being which is rational. Based on evolution of religiosity data in Brazil, crime rates and research based on sites created by Brazilian mothers dedicated to their violently lost beloved sons, messages left by 527,783 participants and interview on those network groups, the research concludes that not only pain is responsible for the growth of religion but hope based on a rational decision. Answers showed that as stated by behavior economic theory people feel worse when has a loss than good when there is a gain but even if the loss was previously known mothers would prefer the gain of having even for a limited time their loved ones and that religion helps to accept the loss because of the hope it offers. So regardless the level of development or pain, it is rational to engage in some religion in one way or another as it contributes to ones improvement of wellbeing. In other words it is not the level of development and welfare that determines religiosity but tradition and rationality.

\section{Acknowledgements}

None.

\section{Conflict of interest}

The author declares no conflcit of interest.

\section{References}

1. The future of World Religion. USA: Pew Research Center; 2013.

2. Murray J, Cerqueira D, Khan T. Crime and Violence in Brazil: Systematic Review of time trends, prevalence rates and risk factors. Agression and Violent Behavior. 2013;18(5):471-483.

3. Robert Barro J, Racher McCleary M. Religion and Economic Growth USA: The National Bureau o Economic Research Working Paper 9682; 2003. $54 \mathrm{p}$.

4. Smith A. An Inquiry into the Nature and Causes of the Wealth of Nations. USA: Modern Library; 1994.

5. Becker GS. The Economic Approach to Human Behavior. USA: University of Chicago Press; 1976. 320 p.

6. Lehrer Evelyn. Religion as a Determinant of Economic and Demographic Behavior in the United States. Institute for the Study o Labor (IZA), Discussion Paper No. 1390. 2004.
7. Iannaccone LR. An Introduction to the Economics of Religion. Journal of Economic Literature. 1998;36(3):1465-1495.

8. Berman Eli, Laitin David. Religion, Terrorism and Public Goods: Testing the Club Model. Journal of Public Economics. 2008;92(10-11):19421967.

9. Barry Kosmin A, Ariela Keysar. American Religious Identification Survey (ARIS 2008). USA: Trinity College, Hartford, Connecticut; 2008. $26 \mathrm{p}$.

10. Census: General Characteristics of the Population, Religion and people with Disability. Brazil: The Brazilian Institute of Geography and Statistics; 2010.

11. Simon HA. Bounded Rationality. In: Eatwell J, et al. editors. The New Palgrave Dictionary of Economics. UK: MacMillan Press Ltd; 1987. 266 p.

12. Tversky A, Kahneman D. Rational Choice and the framing of decisions. Journal of Business. 1986;59(4):S251-S278.

13. Pascal B. Pascal Pensées. USA: Start Publishing; 2012.

14. Eliezer Ayal B, Barry Chiswick R. The Economics of the Diaspora Revisited. Economic Development and Cultural Change. 1983;31(4):861-875.

15. Berman Eli, Laurence Iannaccone R. Religious Extremism: The Good, the Bad and the Deadly. USA: National Bureau of Economic Reasearch Working paper $11663 ; 2005$.

16. Centro Brasileiro de Estudos Latino Americanos(CEBELA), Brazil; 2012.

17. Chiswick Carmel U, Evelyn Lehrer L. Religious Intermarriage: An Economic Perspective. Contemporary Jewry. 1991;12(1):21-34.

18. D'Antonio William V, Mark Cavanaugh J. Roman Catholicism and the Family. In: William D'Antonio V, Joan Aldous, editors. Families and Religions: Conflict and Change in Modern Society. USA: Sage Publications; 1983. p. 141-162.

19. Donahue Michael J, Peter Benson L. Religion and the Well-Being of Adolescents. Journal of Social Issues. 1995;51(2):145-160.

20. Glenn Norval D. The Trend in 'No Religion' Respondents to U.S. National Surveys, Late 1950s to Early 1980s. The Public Opinion Quarterly. 1987;51(3):293-314.

21. Objetivos do Milenio. Institute of Applied Economic Research -IPEA, Brazil; 2010.

22. Khan Habibullah, Bashar Omar. Religion and Development: Are They Complementary? U21 Global Working Paper series, No. 006/2008. 2010.

23. Andrew MasColell, Michael Whinston, Gree Jerry. Microeconomic Theory. USA: Oxford University Press; 1995. 985 p.

24. Sven O. Decision Theory: A Brief Introduction. Sweden: Department of Philosophy and the History of Technology, Royal Institute of Technology (KTH); 2005. 94 p.

25. Waiselfisz Júlio Jacobo. Mapa da Violência 2012. Crianças e Adolescentes do Brasil. Brazil; 2012. 245 p. 